\title{
DEBUNKING CHEMIOSMOSIS AND PROPOSING MURBURN CONCEPT AS THE OPERATIVE PRINCIPLE FOR CELLULAR RESPIRATION
}

\author{
Kelath Murali Manoj \\ Satyamjayatu: The Science and Ethics Foundation, Kulappully, \\ Shoranur-2 (PO), Palakkad District, Kerala, India
}

\section{ABSTRACT}

During cellular respiration, aerobic eukaryotes employ molecular oxygen within the mitochondria, to generate the energy currency of ATP. Chemiosmosis, the long-standing mechanism of mitochondrial oxidative redox metabolism, vouches for the "harnessing of a trans-membrane proton potential" for the synthesis of ATP. Herein, select elements of the chemiosmosis proposal are critically reviewed and debunked. Further, based on simple analogies and structurefunction correlations, murburn concept (connoting to "mured burning" or mild unrestricted burning), the recently established mechanism for microsomal xenobiotic metabolism, is advocated as a probable molecular explanation for mitochondrial oxidative phosphorylation. It is envisaged that the stochastic mechanism of murburn concept could play pivotal roles in several biological redox schemes. The concept necessitates a paradigm shift in mitochondrial biochemistry. Biomed Rev 2017; 28: 31-48.

Keywords: murburn concept, cellular respiration, mitochondrial oxidative phosphorylation, microsomal xenobiotic metabolism, ATP synthesis, chemiosmosis, reactive oxygen species

The new paradigm is not only different but also better, as it (should) adequately explain the anomalies that necessitated the rise of the new system.

Thomas S. Kuhn, The Structure of Scientific Revolutions

\section{INTRODUCTION}

In eukaryotes, mitochondria are the seat of oxidative phosphorylation, a pivotal life process which generates ATP, the ubiquitous cellular energy currency (1). From the early 1950 s to late $1960 \mathrm{~s}$, the primary hypothesis for mitochondrial oxidative phosphorylation (mOxPhos) was proposed by Edward "Bill" Slater (2) and it professed a chemical coupling step sponsored by a high energy enzyme intermediate. Subsequently, Peter Mitchell floated an innovative, specula- tive explanation for OxPhos (sans experimental evidence) in "chemiosmosis, the formation of a trans-membrane proton gradient" (3). Slater's hypothesis was first supported by Paul Boyer with "phosphohistidine" (4), an error that was phased out. Mitchell's proton-pump based mechanism gained traction within the research community (5-8), leading to recognition with a Nobel and a "theory" stature was afforded for chemiosmosis (9). (Paul Boyer had subsequently made a volte face to support chemiosmosis, and that work too was recognized with a Nobel Prize.) Bill Slater was an acclaimed pioneer in

Received 19 November 2017, revised 2 December 2017, accepted 3 December 2017.

Correspondence and reprint request to: Dr Kelath Murali Manoj, Satyamjayatu: The Science and Ethics Foundation Kulappully, Shoranur-2 (PO), Palakkad District, Kerala, India-679122

E-mail: satyamjayatu@yahoo.com 
bioenergetics and championed the field through his research and served as the Editor of Biochimica Biophysica Acta, the leading journal of the then-emerging field of Bioenergetics, for a long period (10). He was a meticulous man of science, who had vehemently disagreed with Mitchell $(11,12)$, and urged researchers on to rethink beyond the chemiosmosis explanation for mOxPhos. Bill passed away last year, without receiving a befitting response to his call. This manuscript answers his [and other seasoned researchers' $(13,14)]$ call and puts forth simple, novel insurmountable arguments that conclusively debunk the chemiosmosis paradigm.

In the cytoplamic membranes (microsomes) of hepatocytes, oxidative metabolism of diverse xenobiotics occurs and this allows humans to get rid of drugs and toxic substances (15). Murburn concept (abstracted from "mured burning" or "mild unrestricted burning") is a "molecule-unbound ion-radical" stochastic interaction and redox mechanistic rationale originally advocated for microsomal xenobiotic metabolism (mXM), with obligatory role for diffusible reactive oxygen species (DROS). Herein, this novel mechanistic paradigm is proposed as a fac-ile explanation for mOxPhos.

The context of the current manuscript focuses on the highly recognized Electron Transport Chain (ETC) - Proton pumps - Chemiosmosis - Rotary ATP synthesis (EPCR) paradigm, as advocated in the contents of three well-known biochemistry textbooks authored by Lehninger, Stryer and Voet (16-18). The details derived from information therein have not been explicitly referenced herein, to avoid redundancy and save space. This intentional faux pas is deeply regretted.

\section{DEBUNKING CHEMIOSMOSIS}

Mechanistic proposals, though "black boxes", must satisfy fundamental laws of physics and justify elementary quantitative rationale. Chemiosmosis fails both these requisites. Figure 1 and its legend capture the essence of the chemiosmosis paradigm for mOxPhos.

\section{Initial state considerations}

The simplest and strongest argument against the chemiosmosis hypothesis rests in accounting protons. The mitochondrion is a bean shaped (cylindrical geometric approximation, with linear dimensions of $0.5 \mu \mathrm{m} \times 1 \mu \mathrm{m}$ ) organelle with a volume of $\sim 0.2 \mu \mathrm{m}^{3}$. At the physiological/neutral $\mathrm{pH}$, the number of protons in a mitochondrion would be:

$$
=\left[\left(6.023 \times 10^{23} \times 5 \times 10^{-8}\right) \times\left(0.2 \times 10^{-15}\right)\right] \approx 6 \text { or }\left(\leq 10^{1}\right)
$$

This does not even meet the requisite of reducing one mol- ecule of oxygen to water, for which the ETC would need 24 protons to be pumped out by a battery of Complex I Complex III - Complex IV (Fig. 1)! The distribution density of the respiratory Complexes is $\sim 10^{4}$ to $10^{5}$ per mitochondrion (19, 20). Therefore, a mitochondrion must conservatively have $\sim 10^{5}$ to $10^{6}$ protons at a given instant, for the proteins (proton pumps) to work at steady state. It is inconceivable that such huge amounts of proteins are present to deal with such miniscule amount of protons. When considering that (i) cristae involutions were not accounted in volume calculations, and (ii) ATP synthesis has also been noted at higher $\mathrm{pH}$ values, the scenario becomes even more incompatible with the fundamental premise of chemiosmosis.

In the mitochondrion, Grotthuss (or "proton hopping") mechanism would ensure adequate proton availability for Krebs 'cycle enzymes' catalytic purposes. However, pumping protons from the matrix to inter-membrane space in a "protonlimited" mitochondrion can only result with the "breaking of water", to alter the intrinsically low ionic product of water. For breaking water, the energetics of dissociation of an $\mathrm{O}-\mathrm{H}$ bond is way beyond the scope of ETC-proton pump energetics and the isothermal physiological cellular system.

Arguments that "dynamic flux of protons from outside" and/or "millimolar levels of intrinsic buffering aids chemiosmosis" must be deemed antithetic because they counter the "closed system" perspective that Mitchellian postulates seek for the formation of a proton-based gradient. Quite simply, if "buffering worked only inside OR both inside and outside matrix", even then the pumping of protons would not lead to any gradient at all, as the change in any $\mathrm{pH}$ would be immediately neutralized. Millimolar levels of preequlibriated resident ions and metabolites cannot serve as proton sources for the amount of protons needed (13). Protons from NADH cannot serve towards pumps because these are required to balance the equation for water formation. Considering the premise that the overall equation of mOxPhos shows a "proton deficiency", the otward proton pumping becomes an even more non-viable thermodynamic proposition in steady state. Also, protons could spontaneously move across phospholipid membranes in millisecond time-frames (21), which is the currently perceived trans-membrane "proton-pumping" time-scale too. So, proton-pumping hypothesis becomes untenable from all perspectives. Therefore, "a TMP formation based on proton pumping across the internal mitochondrial membrane" is a mechanistically unfeasible proposition from the "initial state" 


\section{Cytoplasm}

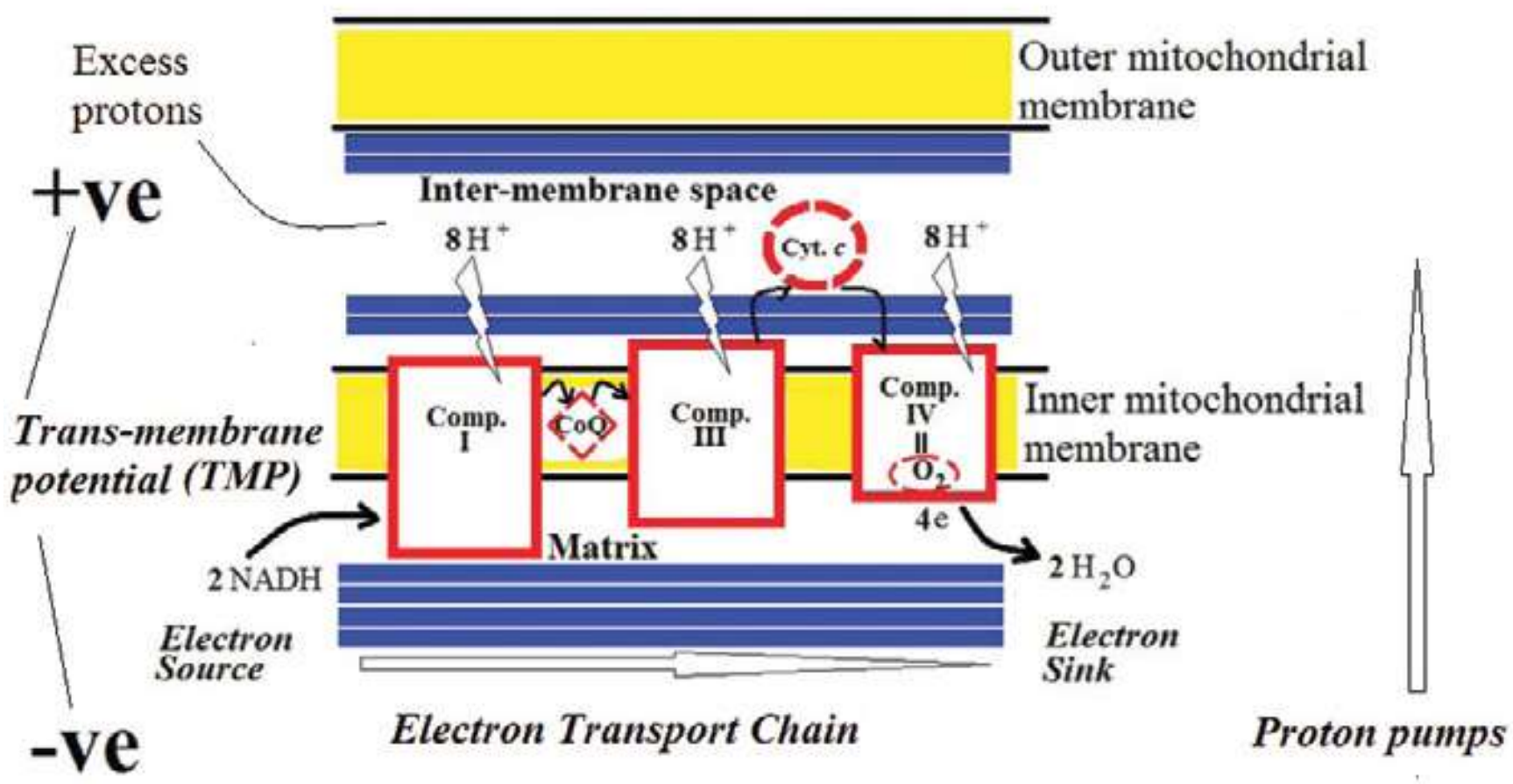

Figure 1. A schematic depiction of the prevailing electron transfer chain and proton pumps for the formation of transmembrane potential (TMP) across the inner mitochondrial membrane. Currently, scientists believe that the Complex I receives electrons from NADH and relays them to the end of the electron transport chain (through a specific electron relay system via $\mathrm{Co} Q$ and $C y t$. c) via Complex III to Complex IV, where the bound oxygen is finally reduced to form water. In the meanwhile, as the electrons pass through the membrane proteins, protons from the matrix are pumped to the intermembrane space, to generate a trans-membrane potential (TMP). In the steady state, owing to this proton concentration difference (inter-membrane space positive, matrix negative) driving force for ATP synthesis is generated, which is harnessed by Complex V. As per the prevailing beliefs, the ETC serves to generate this TMP and oxygen merely serves as the terminal electron sink, forming water. Mobile small molecules are depicted with dashed envelopes. Relatively immobile protein complexes are depicted with red blocks. Defined phase boundaries are shown in black, aqueous and organic milieu are shown with blue and yellow colors respectively. The diagram depicts different macroscopic phase separations, stoichiometry and flow directionalities; and is not drawn to scale.

perspective. Quite simply, such a chemiosmotic machine cannot function in the real world.

\section{Modeling steady-state considerations}

Against all odds, if one concedes that a mitochondrion is a practically working chemiosmotic "Mitchellian" machine (with ample protons, adequate modularity and staggeredsynchronization), it can be modeled starting from an initial state consideration. Here, one need not really worry about the actual number of protons, but only relative concentrations (in the matrix and outside the matrix, within the inter-membrane space) matter. The pictorial representation of such a minimal idealized model is rendered in Figure 2. Now, the temporal variations of TMP under some physiologically relevant scenarios (pH 6 to $\mathrm{pH} 8$ ) are given in Table 1.

Even when starting off with a favorable gradient (case 5 ), the resting potential that results is inadequate; and at least $90 \%$ of the internal protons should still be pumped out at a given instant, to enable the transient potential to reach a value of $\sim 180$ to $200 \mathrm{mV}$, the threshold supposedly required/noted for viable ATP synthesis (22). Even if a $\Delta \mathrm{E}$ was desired between the two temporal points $\mathrm{t} 2$ and $\mathrm{t} 3$ (a sort of alternating temporal potential), then too, minimally $90 \%$ pumping out becomes essential (as seen with case 9). Scenarios 1-3 or 6 may be more realistic ones physiologically, and these also require the pumping of $\sim 99 \%$ of internal protons, to achieve 


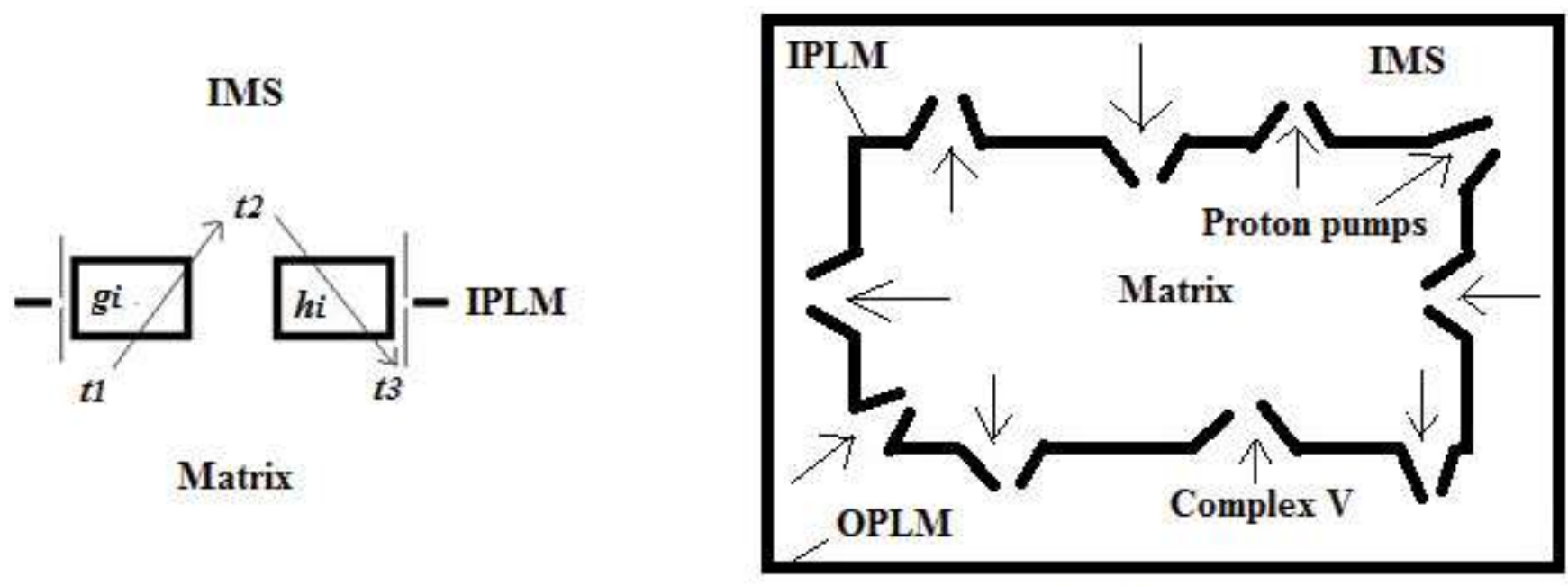

\section{Mitochondrion}

Figure 2. Schematics of outward proton pumps and inward proton channels. On the left, a simple spatio-temporal model of ETC-proton pump (g module) coupled with chemiosmotic proton channel + rotary ATP synthesis" (h module) is constructed. From a given state, the arrows point to the movement of protons in time. The two modules of "ETC + proton pump" and "proton channel + rotary ATP synthesis" are represented by $\mathbf{g}$ and $\boldsymbol{h}$ respectively. The $\mathbf{g}$ module pumps out various extents of the initial matrix proton concentration, within a miniscule time $\Delta t_{i}\left[w h e r e \Delta t_{i}=(t 2-t 1)\right.$ and $\left.\Delta t_{i} \rightarrow 0\right]$. In the second phase, the protons return into the matrix in yet another miniscule time $\Delta t_{f}\left[\right.$ where $\Delta t_{f}=(t 3-t 2)$ and $\left.\Delta t_{f} \rightarrow 0\right]$. Several thousands of such couplets may be present on the inner membrane of any mitochondrion. (IMS = inter-membrane space; IPLM and OPLM stand for inner and outer phospholipid membranes, respectively) On the right, an approximate factual stoichiometry of the $\mathbf{g}$ modules (through purported pumps in Complexes I through IV) and inward proton flux through the $\boldsymbol{h}$ modules (through Complex V) is shown in steady state.

Table 1. Transient potentials (and their dependence on internal protons pumped out) assuming diverse initial states of $\mathrm{pH}$, using the equation $\mathrm{E}=61 \log \left[\mathrm{H}_{\mathrm{O}} \mathrm{H}^{+}\right] /\left[{ }_{\mathrm{i}} \mathrm{H}^{+}\right]$

\begin{tabular}{|c|c|c|c|c|c|c|c|c|c|c|}
\hline \multirow{2}{*}{ No. } & \multirow{2}{*}[\mathbf{H}^{+}]{$_{\mathrm{i}}(\mathbf{n M})$} & \multirow{2}{*}{$\begin{array}{l}{\left[\mathbf{H}^{+}\right]_{0}} \\
(\mathbf{n M})\end{array}$} & \multicolumn{2}{|l|}{ Resting potential (mV) } & \multicolumn{5}{|c|}{$\begin{array}{c}\text { Transient potential }(\mathrm{mV}) \text { at } \mathrm{t} 2 \\
\text { (when various } \% \text { protons are pumped out) }\end{array}$} & \multirow[b]{2}{*}{$\begin{array}{c}\text { t2 } \\
(99.9)\end{array}$} \\
\hline & & & $\begin{array}{l}\text { t1 } \\
(0)\end{array}$ & $\begin{array}{l}\mathbf{t} 2 \\
(1)\end{array}$ & $\begin{array}{c}\text { t2 } \\
(10)\end{array}$ & $\begin{array}{c}\mathbf{t} 2 \\
(\mathbf{5 0})\end{array}$ & $\begin{array}{c}\mathbf{t} 2 \\
(75)\end{array}$ & $\begin{array}{c}\text { t2 } \\
(90)\end{array}$ & $\begin{array}{l}\text { t2 } \\
(99)\end{array}$ & \\
\hline 1 & 10 & 10 & 0 & 1 & 5 & 29 & 52 & 78 & 140 & 201 \\
\hline 2 & 10 & 50 & 43 & 43 & 46 & 64 & 83 & 108 & 169 & 230 \\
\hline 3 & 10 & 100 & 61 & 61 & 64 & 81 & 100 & 124 & 186 & 247 \\
\hline 4 & 10 & 500 & 104 & 104 & 106 & 122 & 141 & 165 & 226 & 287 \\
\hline 5 & 10 & 1000 & 122 & 122 & 125 & 140 & 159 & 183 & 244 & 305 \\
\hline 6 & 50 & 10 & -43 & -41 & -29 & 9 & 35 & 64 & 127 & 188 \\
\hline 7 & 100 & 10 & -61 & -58 & -40 & 5 & 32 & 61 & 124 & 186 \\
\hline 8 & 500 & 10 & -104 & -93 & -53 & 1 & 30 & 59 & 122 & 183 \\
\hline 9 & 1000 & 10 & -122 & -103 & -56 & 1 & 29 & 59 & 122 & 183 \\
\hline 10 & 100 & 100 & 0 & 1 & 5 & 29 & 52 & 78 & 140 & 201 \\
\hline
\end{tabular}

Key values relevant to discussion within the context are highlighted in bold. Since the inner membrane has extensive involutions into the matrix and the outer membrane is permeable, a common volume denomination is taken. 
the threshold voltage. This means that the pumps would have achieved their targets only if there was no buffering, and practically no proton was left within the matrix. Also, even if the proton concentrations were reversed at the initial state (cases 6-9), theoretically, one could achieve the $\Delta$ E solicited. So, if the pumps were "efficient", how is the polarity (unidirectional modality) of the system justified?

Having understood the inconsistency of chemiosmotic logic with the idealized model (in the best case scenario of a staggered-synchronized modular system), it is now opportune to de-/re- construct it to a more realistic physiological plane by revoking the assumption that all proton pumping activities are temporally synchronized. Since Complex V (or the $\boldsymbol{h}$ module) is bidirectional, how can the unregulated and non-synchronized $\boldsymbol{g}$ module know when to stop pumping protons? Surely, an asynchronous proton-pumping exercise cannot afford any significant trans-membrane proton gradient in the steady-state, let alone lead to a potential of $\sim 200 \mathrm{mV}$. Therefore, in a realistic scenario, the purported proton-pumps themselves would be culpable of dissipating potentials by asynchronous working. So, contrary to popular notion, chemiosmosis does not explain uncouplers' (or ionophores') effect on mOxPhos and this argument is further supported by the following authors' writings $(12,13,23,24)$. Now, even if the unimaginable scenario is indulged that fingercountable protons are pumped out to generate high TMP, the potential generated cannot drive the ATP synthesis throughout the mi-tochondrion because power would be too low, owing to very low charge density.

If synchronization of the purported proton pumps is not important, mitochondria can only tap the "potential difference" of the initial $\Delta \mathrm{pH}$ with an open system, and cannot work in a continuous and dynamic process (or steady-state) within a closed system. The "directionally closed system" perspective is a must for chemiosmosis concept. That is- the pumped out protons "need to experience" some drive to come back into the matrix. The image on the right of Figure 2 could help one register this idea. There, a simple vectorial schematic of a single mitochondrion's idealized "proton pumps versus Complex V" distribution (in the ratio of $\sim 6: 4$ ) is shown. Since the numbers of proton pumps are relatively higher than Complex V, one could/would envisage that at most time points, there would be a crowding of the protons at the intermembrane side. (This was the "vision" that Mitchell sold to the world.) But the point to note is that at steady state (without inputs of protons from the outside), the flux is constant in both directions. In steady state, with asynchronized pumping of protons (compounded with a permeable outer membrane), the matrix proton concentration would be at dynamic equilibrium with respect to the inter-membrane space; and a proton gradient cannot exist, even between any two temporal states. If at all a significant proton gradient has to be served into this system (in toto), it must be constantly supplied from the outside or by the inclusion of a chemical gradient term. In any of these imaginable scenarios, there is little point in the proton pumping exercise, rendering chemiosmosis redundant with respect to steady-state.

\section{Elementary thermodynamics reassessed}

Besides the protons' unavailability and non-operability under steady state, the chemiosmosis proposal erroneously assumes that protons "retain energy" upon being pumped out into another disconnected macroscopic phase, and "spontaneously seek" to re-enter the matrix. [Mitchell made an unreal "Moebius loop" type connection here for pumping out protons, the membrane is impermeable (or directionally permeable, say $+180^{\circ}$ ) and for re-entry, the membrane is permeable (or anti-directionally permeable, say $-180^{\circ}$ ). As inferred earlier, such a premise can only be functional through the "intelligent temporal control of mod-ularized setup" and cannot work in steadystate.] This is a violation of "thermodynamic sense", and can be duly demon-strated by the application of law of conservation of energy via a simple mathematical treatment, as follows. Let us consider the elementary aspects of the reaction, as per the prevailing ideas, taking $\mathrm{NADH}$ as the simple starting material

Step 1: NADH $\rightarrow \mathrm{NAD}^{+}+\mathrm{H}^{-}\left(\right.$where $\left.\mathrm{H}^{-} \leftrightarrow{ }_{\mathrm{m}} \mathrm{H}^{+}+2 \mathrm{e}-\right)$

This reaction would be the primary directive source, releasing energy and being spontaneous.

$$
\text { Step 2: }\left(\mathrm{H}^{-} \leftrightarrow{ }_{\mathrm{m}} \mathrm{H}^{+}+2 \mathrm{e}^{-}\right) \rightarrow{ }_{\text {ims }} \mathrm{H}^{+} \| 2 \mathrm{e}^{-} \ldots \ldots . \Delta \mathrm{E}=+\mathrm{x}
$$

Here, energy must be expended to achieve the spatial separation across the inner phospholipid membrane, which could be more than $4 \mathrm{~nm}$ thick, and this energy is derived from Step 1.

$$
\text { Step 3: }{ }_{\text {ims }} \mathrm{H}^{+} \rightarrow{ }_{\mathrm{m}} \mathrm{H}^{+} \ldots \ldots . . \Delta \mathrm{E}=-\mathrm{y}
$$

Now, only a part of the energy released in Step 1 can be harnessed for the proton's return into the matrix phase. The inability of the inner membrane to offer any decent connectivity between the two macroscopic phases does not allow an efficient harnessing of the potential of $x$ either. If this favorable energy term was somehow dependent on Step 2, we can speculate that $|-\mathrm{y}|<<|+\mathrm{x}|$.

Now, by the law of conservation of energy, we can state that-

$$
|-\mathrm{y}| \approx|-\mathrm{p}+\mathrm{x}|
$$

(Alternative expressions, $|-\mathrm{y}| \approx|\mathrm{x}-\mathrm{p}|$ or $|-\mathrm{y}| \approx|-\mathrm{x}+\mathrm{p}|$ would 
be the same as the above. Equating $|-\mathrm{y}| \approx|-\mathrm{p}-\mathrm{x}|$ would make it an impossible energy generating machine! Let's remember that as per the current understanding, it is the spent energy " $+\mathrm{x}$ " that is conserved/recycled.)

Now, if we concede that Step 2 (the matrix to inter-membrane space proton pumping associated with the electron transfer and electron-proton separation) efficiently harnesses most of the energy released in Step 1 and energy terms of Step 4 are minimal, then $|+x| \rightarrow|-p|$. As a consequence,

$$
|-\mathrm{y}| \rightarrow 0
$$

Therefore, it would render such an elaborate process of "Electron Transport Chain-Proton pump-Chemiosmosis-Rotary ATP synthesis" (EPCR) machine untenable or nonviable. [We arrive at this "zugzwang" deduction because Step 1 and Step 3 cannot be energetically connected through Step 2, violating the assumptions we started off with. (That can also be stated as- Step 3 cannot have a negative sign when Step 2 has a positive one. Energy spent is done with, and it cannot be recycled within the same modality.) But this is precisely what the prevailing explanations achieve, and herein, the very same ideas were employed to show the vanity it leads to. The point that is proved in this exercise is that even if we tag along the prevailing explanations, we get nowhere in terms of explaining the energy logic for a viable machine.

\section{The energetics and stoichiometry of ATP synthesis from a holistic perspective}

More seriously, let's disregard every single point discussed earlier and go purely by the fundamental concepts of energetics, as available from literature.

I. If we account for the mechano-energetics of proton pumps alone, we get the efficiency range of $\sim 40$ to $53 \%$ for ATP formation. \{If we take $\sim 35 \mathrm{~kJ} / \mathrm{mol}$ as a conservative val-ue for 1 ATP molecule formation from 3 to 4 protons moving in (each with a maximum free energy value of $\sim 22$ $\mathrm{kJ} / \mathrm{mol})$, we have the efficiency $=[35 /(3$ or $4 \times 22)]=53$ to $40 \%$. $\}$. This process is a subset of the overall redoxcoupled chem-ico-energetics equation, for which we get an overall (average) efficiency of $\sim 48 \%$. \{For the complete oxidation of one molecule each of NADH or $\mathrm{FADH}_{2}$, we get a maximum of 3 or 2 ATP molecules, respectively. Then efficiency $=[(3 \times 35 / 220)=48 \%$ and $(2 \times 35 / 150)$ $=47 \%$ respectively for NADH and $\left.\mathrm{FADH}_{2}\right\}$.] Therefore, the pmf concept affords very little window for any energy loss (even with the best option of 3 protons per ATP) or does not add up to explain the efficiency observed in the system. (When we consider that $\mathrm{Mg}^{2+}$ ions lower the energet- ic terms, the EPCR loses ground even more.) More recently, some respected researchers would want one to "believe in a consensus" (against earlier published data by several research groups) that it is only 2.5 molecules of ATP produced per NADH, to circumnavigate the energetic imbroglio. In that case, it gets into even greater disparity with the calculation shown in II below.

II. If we consider that $\sim 33$ molecules of ATP are formed per glucose molecule oxidized (Since the number of ATP formed per two electrons going through the ETC is "demonstrated to be maximally between 2.5 to $3 \& 1.5$ to 2 for the introduction of the electrons at Complexes I \& II respectively", we could have anywhere between 30 to 36 ATP molecules formed. Therefore, the value of 33 is taken as a midpoint average.), the overall efficiency of biological glucose oxidation would approximate to a value of $\sim 39 \%$. \{The complete oxidation of glucose to six molecules each of carbon dioxide and water is associated with a theoretical energy term of 2937 $\mathrm{kJ} / \mathrm{mol}$. Then, the overall efficiency is given by $(33 \times 35 /$ 2937).\} This value approaches the lower end of the energetic yield of the proton pump scheme alone, giving no scope for energy wastage in any other processes involved in glucose oxidation. (The reactions of glycolysis and Krebs' cycle and all the molecular transports involved would have little rooms for their conduction. And this is when energy losses incurred in the proton pumping out scheme have not been really accounted for).

Quite simply, we have an inadequate proposal in EPCR. Even if we grant it a "working status" (which is a travesty to fundamental reasoning; but which was still indulged!), it fails to explain the chemical logic and physiological energetics of mOxPhos. We can see from the elementary quantitative analyses above that only a significantly higher yielding synthetic process could explain the redox metabolism involved. There were several reports through half a century (25-32) of $\mathrm{P}: \mathrm{O}$ ratios exceeding the conveniently chosen maximal value of 1.5 and 2.5 (for succinate and NADH respectively) by John Walker (Nobel Laureate) group (33). Please see the title of the last paper quoted in the list above, by Lee et al.

- "P/O ratios reassessed: mitochondrial P/O ratios consistently exceed 1.5 with succinate and 2.5 with NAD-linked substrates."(32) Therefore, it is imperative that rather than arriving at some "authority-imposed consensus" (which was in turn powered by the aesthetics of application of "misplaced theories"), the mandate is now on the bioenergetics research community to accept that such higher yields are warranted by cellular metabolism and this mandate has factu- 
ally been experimentally ratified by researchers.

\section{To summate this section}

In retrospect, Mitchell's "chemiosmosis" did not even make semantic sense because osmosis entails the movement of water (the solvent), not protons (the "solute"). It was seen here that: (A) Quantitative logic dictates that the copious amounts of proteins cannot be present to pump the miniscule amounts of protons. (Restated- There are little protons for engaging the purported proton pumps.) (B) The mitochondrial system does not have modularity or staggered synchronization machineries to flip the matrix proton concentrations instantly by several orders of magnitude to practically nil levels in (steady state). (Restated- The protonbased chemiosmosis seeks both zilch and thousands of protons at a given space and time.) (C) There is little direct evidence for proton pumps' operation in steady state and there is no direct connectivity of TMP with proton pumping activity either. Further, there is no 1 electron: 1 proton correlation and the electron transfer routes are many times located away from trans-membrane helices. (D) The chemiosmosis proposal violates the laws of thermodynamics. (Demonstration of ATP synthesis by providing a gradient of $\mathrm{pH}$ or ions at an initial state affects equilibriums. That scenario is incomparable with a steady state consideration and such an experiment cannot be used to infer that a pmf spon-sors the ATP synthesis.) (E) Buffering cannot be quoted as a source of protons, as a gradient can never be built across the membrane if buffers were operative. (F) Respiring cells have also been shown to have much lower potentials than $200 \mathrm{mV}$ and mitochondria can produce ATP even in the absence of $\mathrm{pH}$ gradient. (G) Even after all these inconsistencies are overlooked and every requisite of chemiosmosis proposal ac-ceded to, the purported "theory" fails to account for steady-state and overall energetics. Therefore, chemiosmosis stands conclusively debunked.

\section{MURBURN CONCEPT AS THE OPERATIVE PRINCIPLE FOR MOXPHOS}

The most important thing to note in the context is that when the respiring mitochondrial membrane potentials reached up to $\sim 200 \mathrm{mV}$ (which is the supposed theoretical threshold for efficient ATP synthesis, per the EPCR understanding), it was also associated with an increased detection of diffusible reactive oxygen species, DROS 22). Given - (i) the fact that ETC does not prevent DROS formation, and (ii) the demonstration within this manuscript that chemiosmosis was a "mirage", the involvement of murburn concept (which espouses obligatory roles for DROS in electron transfers and catalyses) could be implicated in ATP synthesis.
In that regard, although the mXM system (which has been explained by murburn con-cept) and mOxPhos systems serve totally different facets of metabolism at seemingly different locales within the cell, the two metabolic routines have an overwhelmingly striking set of analogies.

\section{Similarities in $\mathrm{mXM}$ and mOxPhos systems}

Table 2 presents a comparison between the two systems. At the outset, it can be seen that both these systems have cata-lysts with similar cofactors, the reaction systems employ reduced nicotinamide nucleotides and oxygen at phospho-lipid interface, and water/ROS formation is observed in both systems, etc. The distribution densities are also similar the heme-cofactor containing macromolecules far out-numbering the flavin-cofactor containing proteins. Molecules with similar topography and electrostatics, like dinitrophenol and dihalophenol, "uncouple" electron transfers in both systems.

Figure 3 shows the parallels between the two systems with respect to experimental protocols and observations. The "classical respiration states of mOxPhos" for oxygen consumption (1, 34, 35 and the profiles of $\mathrm{NAD}(\mathrm{PH}$ deple-tion obtained in $\mathrm{mXM}$ are similar (36). In mOxPhos research practice, the sequential addition of reaction components into the mitochondrial suspension (followed by tracking of oxygen utilization with oxygen electrode) is structured/cor-related into four/ five "states". Similarly, in the mXM system, negligible rate (of oxygen uptake and NADH depletion) was observed with CYP alone and a slightly higher rate was obtained with CPR alone, which was affected to various levels with a combination of CYP + CPR (depending on the ratios). A much higher rate was obtained when the xenobiotic substrate was added to CYP + CPR mixture. In both $\mathrm{mXM}$ and mOxPhos research, workers had termed such "apparently non-physiological" trickling/wasting of redox equivalents as "electron leaks". In both systems, the extent of coupling is conditional on system reconstitution and additives/environ-ment. Further, stoichiometry varies significantly across labs and non-integral values are noted for various reaction indices. These observations could imply common chemical reaction logic and thermodynamic controls.

In the last couple of decades, the field of "mitochondrial medicine" has assumed significance (37-40). Some drugs [for example- the commonly used anti-diabetic metformin, supposed to bind Complex I (41)] affect mitochondrial me-tabolism by specific effects whereas several other molecules are supposed to serve as non-specific and generic modulators. Recently, it has also been shown that nutrients (endogenous molecules) can also affect 
Table 2. Similarities and parallels between mOxPhos and $\mathrm{mXM}$ systems

\begin{tabular}{|c|c|c|c|c|}
\hline No & & Attributes & Microsomal system* & Mitochondrial system \\
\hline 1 & \multirow{10}{*}{ 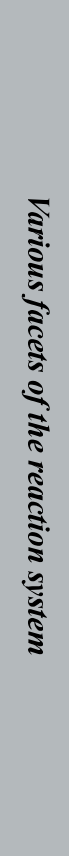 } & Overall reaction & Redox reaction + addition of moiety & Redox reaction + addition of moiety \\
\hline 2 & & Initial electron donor & NADPH & $\mathrm{NADH}$ \\
\hline 3 & & Final electron acceptor & Molecular oxygen $\left(\mathrm{O}_{2}\right)$ & Molecular oxygen $\left(\mathrm{O}_{2}\right)$ \\
\hline 4 & & Obligatory Catalyst 1 & $\begin{array}{l}\text { Reductase (flavoprotein CPR, binds and } \\
\text { uses NADPH); membrane protein }\end{array}$ & $\begin{array}{l}\text { Dehydrogenase (flavoprotein Complex I, } \\
\text { binds and uses NADH); membrane protein }\end{array}$ \\
\hline 5 & & Obligatory Catalyst 2 & $\begin{array}{l}\text { Mixed function oxidase (hemoprotein CYP, } \\
\text { binds and uses oxygen); membrane protein }\end{array}$ & $\begin{array}{l}\text { Oxidase (hemoprotein, Complex IV, binds } \\
\text { and uses oxygen); membrane protein }\end{array}$ \\
\hline 6 & & Ratio of catalysts & Low flavo protein : high Hemo protein & Low flavo protein : high Hemo protein \\
\hline 7 & & Reaction aids & $\begin{array}{l}\text { Hexaligated heme Cyt. } b_{5} \text { ( } \& \mathrm{Fe}-\mathrm{S} \text { proteins } \\
\text { in auxiliary systems) }\end{array}$ & Hexaligated Cyt. $c, \mathrm{Fe}-\mathrm{S}$ proteins $\& \mathrm{CoQ}$ \\
\hline 8 & & $\begin{array}{l}\text { Reaction center-stage (in } \\
\text { vivo/in vitro) }\end{array}$ & Phospholipid interface/vesicles & Phospholipid interface/vesicles \\
\hline 9 & & Reaction of interest & Xenobiotic is hydroxylated & ADP is phosphorylated \\
\hline 10 & & System overview & $\begin{array}{l}\text { Multi-enzymatic ordered sequential scheme, } \\
\text { multi-substrate, multi-product, coupling/un- } \\
\text { coupling phenomena }\end{array}$ & $\begin{array}{l}\text { Multi-enzymatic ordered sequential scheme, } \\
\text { multi-substrate, multi-product, coupling/un- } \\
\text { coupling phenomena }\end{array}$ \\
\hline 11 & \multirow{10}{*}{ 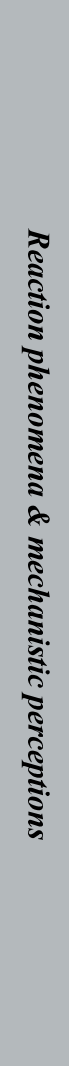 } & $\begin{array}{l}\text { Partitioning of substrate and } \\
\text { product at the membrane }\end{array}$ & $\begin{array}{l}\text { The hydroxylated product has a lesser } \log \mathrm{P} \\
\text { value than the substrate. }\end{array}$ & $\begin{array}{l}\text { Log P value of ADP is }-2.6 \text { and that of ATP } \\
\text { is }-5.5 \text {. }\end{array}$ \\
\hline 12 & & Electron transfer & $\begin{array}{l}\text { Long range, outer sphere mechanism; } \\
\text { Essentially two-electron process overall, } \\
\text { could involve one-electron step(s); electron } \\
\text { can be exchanged from/to the system by } \\
\text { redox-active additives }\end{array}$ & $\begin{array}{l}\text { Long range, outer sphere mechanism; } \\
\text { Essentially two-electron process overall, } \\
\text { could involve one-electron step(s); elec- } \\
\text { trons can be exchanged from/to the system } \\
\text { by redox-active additives }\end{array}$ \\
\hline 13 & & Protons & Extraneous proton consumed & Extraneous proton consumed \\
\hline 14 & & Thermodynamic drive & $\begin{array}{l}\text { Overall downhill, push of electrons from } \\
\text { lower to higher redox potential, through di- } \\
\text { rect protein-protein contact }\end{array}$ & $\begin{array}{l}\text { Overall downhill, push of electrons from } \\
\text { lower to higher redox potential, through } \\
\text { direct protein-protein contact }\end{array}$ \\
\hline 15 & & Substrate binding & $\begin{array}{l}\text { Xenobiotic binds to catalyst } 2 \text { for pro- } \\
\text { longed time frame and waits for catalytic } \\
\text { cycle to get completed }\end{array}$ & $\begin{array}{l}\text { Oxygen binds to catalyst } 2 \text { for prolonged } \\
\text { time frame and waits for catalytic cycle to } \\
\text { get completed. }\end{array}$ \\
\hline 16 & & Water formation & Catalyst 2 forms water & Catalyst 2 forms water \\
\hline 17 & & ROS involvement & $\begin{array}{l}\text { ROS formed as a deleterious side reaction, } \\
\text { due to uncoupling }\end{array}$ & $\begin{array}{l}\text { ROS formed as a deleterious side reaction, } \\
\text { due to uncoupling }\end{array}$ \\
\hline 18 & & Inhibitors like $\mathrm{CO}$ and $\mathrm{CN}^{-}$ & Bind to Fe-center of catalyst 2 & Bind to Fe-center of catalyst 2 \\
\hline 19 & & Salient uncouplers & Dihalophenolics & Dinitrophenolics \\
\hline 20 & & Overall stoichiometry & $\begin{array}{l}\text { Subject to change by alteration of reaction } \\
\text { microenvironment and non-integral values } \\
\text { of ratios noted }\end{array}$ & $\begin{array}{l}\text { Subject to change by alteration of reaction } \\
\text { microenvironment and non-integral val- } \\
\text { ues of ratios noted }\end{array}$ \\
\hline
\end{tabular}

* Many of the mechanistic perceptions in the microsomal system stand corrected; they are presented herein only to draw an existential analogy. 

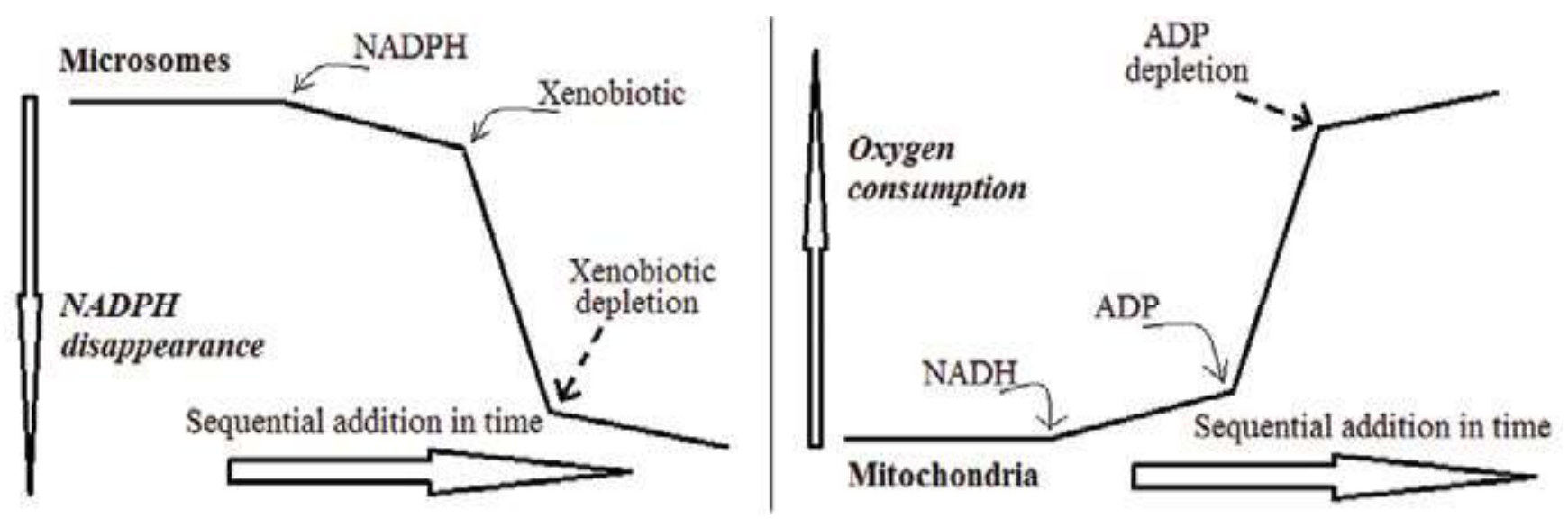

Figure 3. Similarities and parallels in $\mathrm{mXM}$ and mOxPhos experimental systems.

and effect drug metabolism and interactions in mitochondria and cells (42). These effects are quite similar to mXM system observations with respect to drug metabolism inhibitions and drug-drug interactions (43). Many drugmetabolizing cytochrome P450s (CYPs) like 1A1, 2B1, $2 \mathrm{E} 1,2 \mathrm{D} 6,3 \mathrm{~A} 1$, etc. are also found in mitochondria (44-46) and they are known to need the other mi-tochondrial membrane proteins for achieving their activity. Though rare, non-specific phosphorylation of xenobiotics has also been observed (47). Therefore, (i) mitochondria pose immense pharmacodynamic and pharmacokinetic significance (48) and (ii) there are strong reasons to believe that murburn concept could be operative in mOxPhos too. Another connecting link is the thought-line that during the primary stages of evolution of life, there would not have been very highly specialized/specific systems for mixed-oxidase functionalities. In that light, stochastically ordered reaction logic like murburn concept could have spontaneously formed and driven fundamental life processes. In this perspective, the idea presented herein is a probable proposal that scientists might want to reflect upon and explore.

\section{The essential scheme of murburn perspective for mOxPhos}

Reaction schema shown in Figure 4 and equations shown in Box 1 capture the essence of murburn explanation for mOxPhos. Further, Table 3 makes a preliminary comparison of the shift in perceptions and roles of reaction components. It can be envisaged that murzymes (enzymes that mediate unrestricted redox catalysis/reactions) of various redox potentials, Complex I, II and III, initiate one-electron reaction from the substrates $\mathrm{NADH}$, succinate and $\mathrm{CoQH}_{2}$ respectively, generating one-electron equivalents in the milieu, which could be (enzymatically or non-enzymatically) relayed to oxygen on the inside or elsewhere, CoQ within the membrane and Cyt. $c$ in the IMS of the mitochondrion. CoQ or ubiquinone need not be seen as a two-electron agent alone, its one-electron reduced form is also quite stable and would serve to enhance radical lifetimes in the vicinity of the membrane. (But the formation of $\mathrm{CoQH}_{2}$ is very important, to establish a local two-electron sink reaction; without which DROS have little fruitful lifetimes.) The presence of various metal centers on the different proteins (of varying redox potentials) is to have catalysts in various redox potential ranges so that the radical formation and release would be smoothly transitioned and consistently maintained. Therefore, it is now understood that mitochondria primarily achieves a low-water, low-proton microenvironment. The outer phospholipid membrane forms the outer dome of the reactor and Cytochrome $c$ (functioning as a one-electron scavenger within the inter-membrane space) is the last barrier to prevent the escape of one-electron equivalents. Complex IV can accept the redox equivalents from Cytochrome $c$ and bring it back to the internal murzone, and also stabilize/reduce superoxide and further generate hydroxyl radical and singlet oxygen. Complex III could reestablish a one-electron paradigm and perhaps recycle the $\mathrm{DROS} / \mathrm{CoQH}_{2}$ that was formed in the internal membrane. Complex V serves as a proton server to the matrix and it could have evolved later on, to meet the proton deficiency involved in physiological oxidative phosphorylation reactions. It is through the conduit of DROS that both coupled and uncoupled reactions occur. The reaction logic does not seek compartmentalization or multi-molecular ordered/ se- 


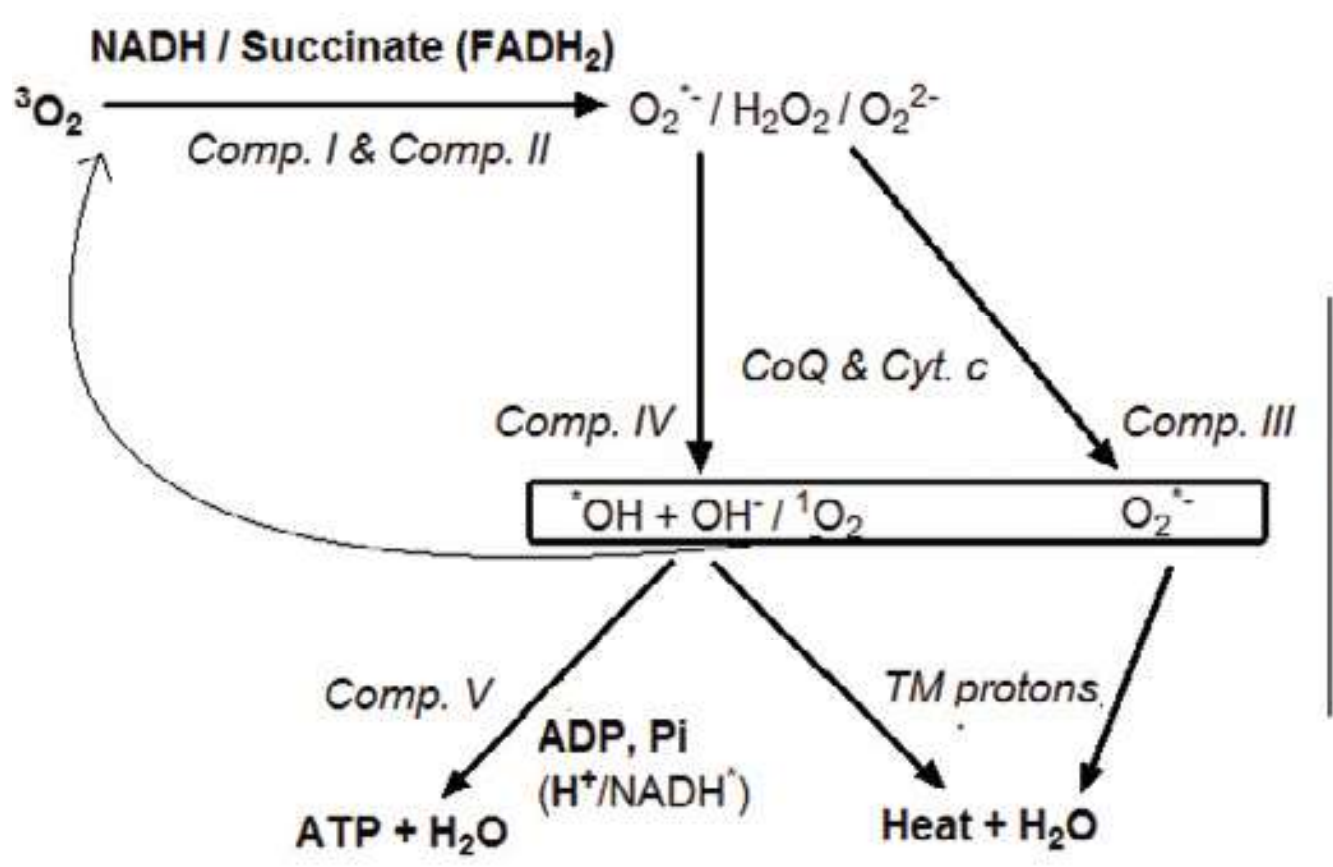

\section{Trans-membrane}

Figure 4. A minimal reaction scheme of mOxPhos, as conceived by murburn concept. Complex I and II are involved in the generation and moderation of DROS (from singlet and triplet oxygen) whereas Complex III and IV work to stabilize or modify the DROS. Complex $V$ serves for proton equilibrium. Some components could play multiple roles in the overall scheme, depending on the various stages that the reaction cocktail could evolve to. It is through the common conduit of DROS that ATP, water and heat are generated. DROS (particularly, the key reactive intermediates given in the second tier box) may serve both as catalysts or reactants in the system. Catalysts are represented in italics whereas reactants and products are given in bold. The scheme is rather unordered (stochastic) and reactions are primarily bimolecular, not seeking multi-molecular complexations. $N A D H$ could go through one or two electron routes, within milieu (and this is shown with $N A D H^{*}$ ).

\section{Box 1}

$$
\begin{aligned}
& \mathrm{NADH}+\mathrm{O}_{2} \rightarrow \mathrm{NAD}^{+}+\mathrm{HO}_{2}^{-} \underline{\mathrm{OR}} \mathrm{NADH}+2 \mathrm{O}_{2} \rightarrow \mathrm{NAD}^{+}+2 \mathrm{O}_{2}{ }^{*_{-}}+\mathrm{H}^{+}(1) \\
& \mathrm{CoQH}_{2} / \mathrm{FADH}_{2}+\mathrm{O}_{2} \rightarrow \mathrm{CoQ} / \mathrm{FAD}+\mathrm{H}_{2} \mathrm{O}_{2} \underline{\mathrm{OR}} \mathrm{CoQH}_{2} / \mathrm{FADH}_{2}+2 \mathrm{O}_{2} \rightarrow \mathrm{CoQ} / \mathrm{FAD}+2 \mathrm{O}_{2}^{*}+2 \mathrm{H}^{+}(2) \\
& \mathrm{NADH}+\mathrm{CoQH}_{2} / \mathrm{FADH}_{2}+3 \mathrm{O}_{2} \rightarrow \mathrm{NAD}^{+}+\mathrm{CoQ} / \mathrm{FAD}+\mathrm{H}_{2} \mathrm{O}_{2}+2 \mathrm{O}_{2}{ }^{*}+\mathrm{H}^{+} \text {(3) } \\
& \text { In the milieu (or in Complex IV's vicinity), now- } \\
& \mathrm{H}_{2} \mathrm{O}_{2}+\mathrm{O}_{2}{ }^{*-} \rightarrow{ }^{1} \mathrm{O}_{2}+\mathrm{OH}^{-}+\mathrm{OH}^{*}(4) \\
& \mathrm{H}^{+}+\mathrm{OH}^{-} \rightarrow \mathrm{H}_{2} \mathrm{O}(5) \\
& \mathrm{NADH}+\mathrm{CoQH}_{2} / \mathrm{FADH}_{2}+2 \mathrm{O}_{2} \rightarrow \mathrm{NAD}^{+}+\mathrm{CoQ} / \mathrm{FAD}+\mathrm{H}_{2} \mathrm{O}+\mathrm{O}_{2}{ }^{{ }_{-}}+\mathrm{OH}^{*}(6) \\
& \text { Or, for one oxygen molecule, the equation is- } \\
& \mathrm{NADH}+\left(\mathrm{C}_{4} \mathrm{H}_{4} \mathrm{O}_{4}\right)^{2-}+\mathrm{O}_{2} \rightarrow \mathrm{NAD}^{+}+\left(\mathrm{C}_{4} \mathrm{H}_{2} \mathrm{O}_{4}\right)^{2-}+\mathrm{H}_{2} \mathrm{O}+\mathrm{OH}^{-}(7)
\end{aligned}
$$

Concomitantly, the radicals produced above also serve as couplers in the matrix reaction:

$$
\text { Ad-O- }\left(\mathrm{PO}_{2}\right)^{-}-\mathrm{O}-\left(\mathrm{PO}_{3}\right)^{2-}+\mathrm{HPO}_{4}^{2-}+\mathrm{H}^{+} \rightarrow \text { Ad-O- }\left(\mathrm{PO}_{2}\right)^{--O}-\left(\mathrm{PO}_{2}\right)^{--O}-\left(\mathrm{PO}_{3}\right)^{2-}+\mathrm{H}_{2} \mathrm{O}(8)
$$

As evident, the scheme requires protons' entry into matrix for equilibration. 
quential events. It was already demonstrated that such oneelectron processes could be mild, reproducible, specific/selective and inherently constitutive in nature (36). The result-ing process is simple, functional and affords a viable chemi-cal coupling modality in the physiological redox ranges. In the context of mitochondrial reaction system, murburn concept's operation could be analogous to a nuclear fission reactor. Only herein, a radical reaction is initiated, moderated, maintained and quenched. These dynamic in situ gen-erated radicals mediate the coupling of phosphate to ADP.

As per murburn concept, the reactions proceed obligatorily through DROS and accumulation of these leads to the generation of TMP. The system does not solicit outward proton pumping machineries at the phospholipid interface. Also, the logic is predominantly a one-electron paradigm that invokes the involvement of oxygen at multiple points (in space and time) and all reactions in this scheme are bi-molecular, brought about in free solution or catalyzed by a protein around the phospholipid interface. Jagendorf's in vitro experiments can be explained by the simple considera-tion that the closed vesicular system with ADP and Pi would need protons for the synthesis of an ester bond, because the protagonists' $\mathrm{pK}_{\mathrm{a}}$ values are near neutral $\mathrm{pH}$ (Box 1). This equilibrium-driven reaction is quite distinct from the physiological phosphorylation.

Table 3. Comparison of the prevailing EPCR hypothesis and the newly proposed murburn concept explanations for mOxPhos

\begin{tabular}{|c|c|c|c|c|}
\hline No. & & Attribute / Item & Chemiosmosis & Murburn concept* \\
\hline 1 & \multirow{4}{*}{ 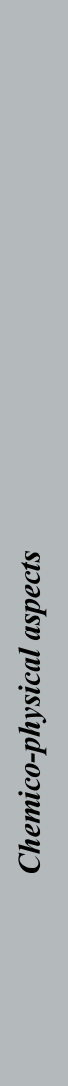 } & $\begin{array}{l}\text { Nutshell of reaction } \\
\text { paradigm }\end{array}$ & $\begin{array}{l}\text { Multi-molecular ordered assemblies dictate a } \\
\text { vitally deterministic course of events. Electron } \\
\text { and proton separation over long distance and } \\
\text { time across a phospholipid-embedded electron- } \\
\text { ic circuitry leads to a proton/chemical gradient; } \\
\text { this energy is tapped by a molecular motor } \\
\text { enzyme to synthesize ATP. }\end{array}$ & $\begin{array}{l}\text { At low proton and water activity, radicals } \\
\text { generated in a lipid interface afford phos- } \\
\text { phorylation. Random collisions between } \\
\text { molecules or ions or radicals afford high } \\
\text { kinetic viability; equilibrium forces and } \\
\text { stochastic factors (including spin barriers) } \\
\text { dictate reaction fates. }\end{array}$ \\
\hline 2 & & $\begin{array}{l}\text { Outlay of reaction } \\
\text { scheme }\end{array}$ & $\begin{array}{l}\text { In the matrix side of the mitochondrial inner } \\
\text { membrane, electrons are stripped from NADH } \\
\text { and succinate, to be run down a "redox po- } \\
\text { tential slope" (by a thermodynamic push); the } \\
\text { energy released through some of these inter- } \\
\text { molecular transfers is used to pump protons } \\
\text { across the inner membrane (through a complex } \\
\text { route within the proteins); then the protons' } \\
\text { spontaneous flux back to the matrix is used } \\
\text { to drive ATP formation by a molecular motor, } \\
\text { which functions by conformational changes. }\end{array}$ & $\begin{array}{l}\text { Flavo- and metallo-enzymes (in the pres- } \\
\text { ence of reducing substrates, oxygen and } \\
\text { mobile redox active agents) set up a moder- } \\
\text { ated relay of one- and two- electron reaction } \\
\text { equilibriums within the mitochondrial inner } \\
\text { membrane-matrix interface; formation of } \\
\mathrm{CoQH}_{2} \text {, water and phosphorylated products } \\
\text { serve as two-electron sinks, pulling the } \\
\text { overall reaction forward by a thermodynam- } \\
\text { ic tug exerted by the terminal reactions. }\end{array}$ \\
\hline 3 & & $\begin{array}{l}\text { Coupling link between } \\
\text { redox reaction and } \\
\text { phosphorylation }\end{array}$ & $\begin{array}{l}\text { No chemical connection, but a highly indirect } \\
\text { electro-mechanical connection. }\end{array}$ & $\begin{array}{l}\text { The formation of oxygen centered reactive } \\
\text { intermediates directly aids phosphorylation. }\end{array}$ \\
\hline 4 & & $\begin{array}{l}\text { Electron transfer mo- } \\
\text { dality }\end{array}$ & $\begin{array}{l}\text { Outer sphere model within protein, sequence } \\
\text { of connected/charted events involving redox } \\
\text { centers of proteins and small molecules in close } \\
\text { proximity; movement/transfer of electrons } \\
\text { primarily as pairs, via collisions or connectivity } \\
\text { or supra complexes. }\end{array}$ & $\begin{array}{l}\text { Molecule-ion-radical interactions scheme; } \\
\text { may involve some outer sphere ET, but not } \\
\text { obligatory; randomized one- and two- elec- } \\
\text { tron reactions moderated at the membrane- } \\
\text { matrix interface, with provisions for recy- } \\
\text { cling of lost electrons. }\end{array}$ \\
\hline 5 & & $\begin{array}{l}\text { Thermodynamics and } \\
\text { kinetics }\end{array}$ & $\begin{array}{l}\text { Essentially a push of electrons from lower to } \\
\text { higher redox potential centers; followed or syn- } \\
\text { chronized with torque generation by a mecha- } \\
\text { nized molecular motor (tapping into the gener- } \\
\text { ated trans-membrane proton cum electro-chem- } \\
\text { ical gradient). }\end{array}$ & $\begin{array}{l}\text { Shifting of one-electron equilibrium of oxy- } \\
\text { gen-superoxide to the right by two-electron } \\
\text { reactions occurring primarily in the matrix } \\
\text { side of the inner membrane. pH and ionic } \\
\text { strength could alter the equilibriums. "Spin" } \\
\text { could control/regulate crucial steps. }\end{array}$ \\
\hline 6 & & $\begin{array}{l}\text { Summation of overall } \\
\text { redox reaction }\end{array}$ & $\begin{array}{l}\mathrm{NADH}+\left(\mathrm{C}_{4} \mathrm{H}_{4} \mathrm{O}_{4}\right)^{2-}+\mathrm{H}^{+}+\mathrm{O}_{2} \rightarrow \mathrm{NAD}^{+}+ \\
\left(\mathrm{C}_{4} \mathrm{H}_{2} \mathrm{O}_{4}\right)^{2-}+2 \mathrm{H}_{2} \mathrm{O}\end{array}$ & $\begin{array}{l}\mathrm{NADH}+\left(\mathrm{C}_{4} \mathrm{H}_{4} \mathrm{O}_{4}\right)^{2-}+\mathrm{O}_{2} \rightarrow \mathrm{NAD}^{+}+ \\
\left(\mathrm{C}_{4} \mathrm{H}_{2} \mathrm{O}_{4}\right)^{2-}+\mathrm{H}_{2} \mathrm{O}+\mathrm{OH}^{-}\end{array}$ \\
\hline
\end{tabular}




\begin{tabular}{|c|c|c|c|c|}
\hline 7 & \multirow{2}{*}{ 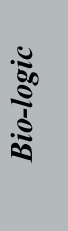 } & $\begin{array}{l}\text { Evolutionary perspec- } \\
\text { tive }\end{array}$ & $\begin{array}{l}\text { The whole machinery and process is aimed at } \\
\text { reducing ROS formation. }\end{array}$ & $\begin{array}{l}\text { The whole machinery is evolved for an ef- } \\
\text { fective utilization of DROS. }\end{array}$ \\
\hline 8 & & Physiological outlook & $\begin{array}{l}\text { Highly sophisticated machineries and processes } \\
\text { set as pre-requisites for energy transduction } \\
\text { mechanism. }\end{array}$ & $\begin{array}{l}\text { Within the physiological redox window } \\
(-400 \text { to }+800 \mathrm{mV}) \text {, rapid radical reactions } \\
\text { synthesize energy currency. }\end{array}$ \\
\hline 9 & 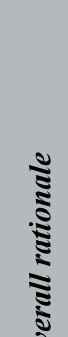 & $\begin{array}{l}\text { Reducibility and } \\
\text { Assumptions }\end{array}$ & $\begin{array}{l}\text { Challenges Ockham's razor, A vectorial and } \\
\text { complicated model that requires a sequentially } \\
\text { ordered process. Proteins (and their complexes) } \\
\text { need to have functional/mechanistic ability to } \\
\text { sense and tap electrical potential and concen- } \\
\text { tration gradients. Charge and mass transport } \\
\text { across two macroscopic phases involved. The } \\
\text { scheme demands and promises high fidelity and } \\
\text { redproducibility. }\end{array}$ & $\begin{array}{l}\text { Aligns with Ockham 's razor, minimalist } \\
\text { model that has independent randomized } \\
\text { events confined to the phospholipid inter- } \\
\text { face. Molecules have predictable properties } \\
\text { but the reaction scheme with such agents } \\
\text { could be associated with significant levels } \\
\text { of uncertainty. Reaction logic necessitates } \\
\text { spatial confinement of intermediates. }\end{array}$ \\
\hline
\end{tabular}

For simplicity: A water mill or hydroelectric power plant.

For complexity: engine, dynamo and battery of an automobile.
For simplicity- an ordinary hearth.

For complexity- a nuclear fission reactor.
Relatively insignificant role; involved in the end of ETC as the terminal electron acceptor, bound at Complex IV alone
Quintessence of mOxPhos; Reacts in the initial phase; involved in a multitude of reactions and equilibriums; omnipresent conduit

One or two electron reaction at Complex I and could have secondary roles; proton deficiency important

Seen as 2-electron donor to Complex I

Bound status to Complex V; required for ETC and phosphorylation

Could potentially bind to several sites besides Complex V

Bound status to Complex V; required for ETC and phosphorylation
Pi activation occurs in murzone

Involved in several reactions and equilibriums in the redox processes within the matrix and spontaneously moves inward

NADH oxidase (a murzyme) Owing to its structural feature, proton deficiency within NADH and omnipresent oxygen molecule, provides one electron into the oxygen-superoxide equilibrium. CoQ can get one or two electrons into the lipid membrane from one or two NADH molecules' oxidation. forms the "chassis" for respirasome.

Succinate dehydrogenase AND Ubiquinone reductase (and CoQ recycle proton supplier) Catalyzes two hydride ion transfers to CoQ, forming $\mathrm{CoQH}_{2}$

Succinate dehydrogenase, $\mathrm{FADH}_{2}$ oxidase AND Ubiquinone reductase Catalyzes the generation of superoxide, could also generate $\mathrm{CoQH}_{2}$.

Ubiquinone-cytochrome c oxidoreductase and proton pump Intra-membrane electron conduit, transferring two-electron equivalents from one molecule of $\mathrm{CoQH}_{2}$ to two molecules of Cyt $c$ (accompanied by a very complex $Q$ cycle); pumps four protons out of the matrix.

A murzyme with trans-membrane bifuctionality Projects that this component recycles the two-electrons lost into the membrane (to form $\mathrm{CoQH}_{2}$ or $\mathrm{CoQH}$ ) by transferring one electron equivalent to oxygen in the matrix side and one electron to Cyt $c$ in the intermembrane space. 


$\begin{array}{lll}\text { Complex IV } & \begin{array}{ll}\text { A complex murzyme } \\ \text { Recycles the electron lost to cytochrome } c \\ \text { by transferring it to oxygen; and/or transfers } \\ \text { Transfers 4 protons and four electrons to a } \\ \text { long-term bound oxygen, to release two mol- } \\ \text { ecules of water; pumps four protons out of the } \\ \text { matrix }\end{array} & \begin{array}{l}\text { it to the bound superoxide thereby reducing } \\ \text { it to form peroxide; forms water because of } \\ \text { superoxide + peroxide reaction in its vicin- }\end{array} \\ & \begin{array}{l}\text { ity (this gives a two-electron sink and a tug). } \\ \text { Exact functions to be ascertained. }\end{array}\end{array}$

20 Complex V
Driven by protons and works well in both directions, as ATPase and ATPsynthase.
Could serve to bring in protons and in driving equilibrium centered reactions as an ATPase; could work as ATPsynthase in equilibrium driven conditions.

\begin{tabular}{|c|c|c|c|c|}
\hline 21 & & Cytochrome $c$ & $\begin{array}{l}\text { One electron relay agent from Complex III to } \\
\text { Complex IV. }\end{array}$ & $\begin{array}{l}\text { Electron scavenger in the IMS; recycles by } \\
\text { giving electrons off to Complex IV. }\end{array}$ \\
\hline 22 & \multirow{7}{*}{ 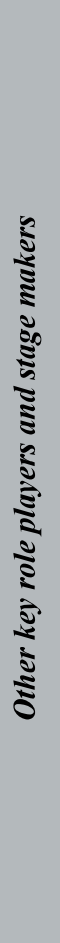 } & CoQ & $\begin{array}{l}\text { Diffusible 2-electron relay agent transferring } \\
\text { two electron equivalents from Complexes I and } \\
\text { II to Complex III }\end{array}$ & $\begin{array}{l}\text { Serves as 1-electron and 2-electron redox } \\
\text { agent across a wide redox window within } \\
\text { the phospholipid membrane }\end{array}$ \\
\hline 23 & & Ions & Lead to electrical potential build up & $\begin{array}{l}\text { Lead to charge relay facilitation and } \\
\text { equilibrium effects }\end{array}$ \\
\hline 24 & & ROS & Deleterious product formed in oxidative stress & $\begin{array}{l}\text { Obligatory intermediacy of superoxide/ } \\
\text { hydroxyl radicals and agents like singlet } \\
\text { oxygen and peroxide }\end{array}$ \\
\hline 25 & & Cardiolipin & $\begin{array}{l}\text { Structural component for respirasomes and } \\
\text { renders ETC + proton pumping efficient, as it } \\
\text { traps protons }\end{array}$ & $\begin{array}{l}\text { Enables better conservation of superoxide } \\
\text { equivalents within the murzone by high } \\
\text { negative charge density }\end{array}$ \\
\hline 26 & & $\begin{array}{l}\text { Inner membrane \& } \\
\text { TMP }\end{array}$ & $\begin{array}{l}\text { Chief regulator, selectively permeable, serves } \\
\text { to maintain a (proton/chemical gradient) } \\
\text { potential difference across itself. Proton- } \\
\text { pumping leads to TMP, which acts as tour-de- } \\
\text { force for ATP synthesis. }\end{array}$ & $\begin{array}{l}\text { Serves to house and anchor murzymes that } \\
\text { mediate radical reactions at the phospholipid } \\
\text { interface. TMP (a side-event) builds up due } \\
\text { to abundance of negative species in matrix. }\end{array}$ \\
\hline 27 & & Outer membrane & Present to concentrate protons & Present to prevent the escape of radicals \\
\hline 28 & & Matrix & $\begin{array}{l}\text { Reactions occurring within matrix are } \\
\text { inconsequential to ETC or phosphorylation }\end{array}$ & $\begin{array}{l}\text { Reactions within matrix govern the overall } \\
\text { rates and outcomes }\end{array}$ \\
\hline 29 & \multirow{5}{*}{$\frac{\vdots}{5}$} & ATP & $\begin{array}{l}\text { Formed at Complex } \mathrm{V} \text { by rotational catalysis } \\
\text { by the mechanical push afforded by the inward } \\
\text { movement of protons }\end{array}$ & $\begin{array}{l}\text { Perhaps formed in murzone and more } \\
\text { efficiently in the presence of Complex V, } \\
\text { associated with protons' inward movement } \\
\text { (Investigate) }\end{array}$ \\
\hline 30 & & $\mathrm{NAD}^{+}$ & Formed spontaneously at Complex I & Formed in the matrix/Complex I \\
\hline 31 & & Fumarate & Formed spontaneously at Complex II & Formed spontaneously at Complex II \\
\hline 32 & & Water & Formed at Complex IV and Complex V & Formed primarily in matrix side of murzone \\
\hline 33 & & Hydroxide ion & Not involved in the overall equation & $\begin{array}{l}\text { Generated in the matrix side of the inner } \\
\text { membrane; serves to enhance the longevity } \\
\text { of radicals }\end{array}$ \\
\hline
\end{tabular}




\begin{tabular}{llll}
\hline 34 & $\begin{array}{l}\text { Inhibitors like } \\
\text { rotenone, carboxin, etc. }\end{array}$ & Disrupt ETC by binding to Complex I and II & $\begin{array}{l}\text { Take away activity of the component } \\
\text { by altering the redox status of center by } \\
\text { covalent/affinity binding; preventing a 2e } \\
\text { sink in vicinity }\end{array}$ \\
3 & $\begin{array}{l}\text { Low amounts of } \\
\text { inhibitors like cyanide, } \\
\text { CO, etc. }\end{array}$ & Disrupt ETC by binding to Complex IV & $\begin{array}{l}\text { Prevent the build-up and cycle of } \\
\text { physiologically necessary radicals/DROS } \\
\text { Uncouplers, } \\
\text { Uncoupling proteins }\end{array}$ \\
\hline
\end{tabular}

* The precise/accurate functions of all membrane proteins and complexes need to be re-investigated and re-assigned with respect to the murburn perspective. The functions listed in the table provide only a theoretical projection.

\section{Support for murburn concept's relevance in $\mathrm{mOxPhos}$}

The organization of mitochondria with only cristae invaginations and two membranes agrees well with murburn concept. The scattered distribution of proteins (or supercomplexes) shows low amounts of Complex I and II (DROS generators) and high amount of Complex IV (DROS stabilizer); and this is solicited by murburn concept. High levels of Cyt $c$ and copious amounts of CoQ also align well with the allocated one-electron scavenging/recycling roles within the IMS and IPLM respectively. The matrix-ward projections of Complex I and II and the fact that the redox centers therein are not aligned with a linear increasing order of redox potentials point to deliberate ploys by evolution for aiding DROS formation. Further, murburn concept also rationalizes that the "electron transfer routes" are away from trans-membrane helices of these proteins. The fact that there are "non-route redox centers" (within Complex I and II) is rationalized by murburn concept. The erstwhile consideration required the inner mitochondrial membranes to be discriminatory and regulatory in structure and function. The mitochondrial membranes are seen herein as a hydrophobic interface that could potentially support and confine radical reactions. For all practical purposes, mitochondrial membranes do not show "super-deterministic" ability/features. (The fact that they have high protein content could affect their selectivity and permeability features, though.) This consideration aligns well with the mandate that murburn concept allocates them. It may explain the influence of membrane lipids like cardiolipin. Their high negative charge densities on their lipid-assembled periphery would keep superoxide and hydroxide in the matrix side of the membrane interface, thereby enhancing phosphorylation yields. Further, the concept remained a conundrum as to how the $c$-subunits' trans-membrane domain of Complex $\mathrm{V}$ could latch on to the frail inner membrane (with only $20 \%$ lipids) and rotate at the same time (that too, merely by the inward move-ment of protons), while the $\gamma$ shaft ploughed through the $\mathrm{F}_{1}$ subunit. With the murburn scheme, this predicament is averted. A conformation change within the $F_{1}$ domain (induced by the binding of ATP to Complex V in the matrix) could be relayed by the $\gamma$ shaft at the stationary $\mathrm{F}_{\mathrm{o}}$ domain. Thus, the relative movement of the $\gamma$ shaft between two stationary domains would serve to bring in protons for chemostasis. This way, the structural integrity and functionality (inhibition by oligomycin) of the membrane-embedded Complex V could be better explained. A schematic crosssectional representation of the salient participants involved in mOxPhos is shown in Figure 5a and their surface distribution is shown in Figure 5b. From these schemes, it can be inferred that the distribution densities and structural features of all protagonists agree well with the roles accorded by murburn concept.

\section{To summate this section}

Using analogies with $\mathrm{mXM}$ system and deducing from the structural/compositional features of mitochondria, a novel stochastic reaction scheme for mOxPhos was proposed. A critical dissection of the remaining elements of the EPCR theory (ETC and rotary ATP synthesis) is thus warranted. Further, several arguments on evolutionary considerations, reaction chemistry logic (particularly, the role of oxygen, the quintessence of mOxPhos), direct evidences for DROS involvement, unraveling of long-standing conundrums, new predicted experiments, etc. stand to endorse the relevance of murburn concept in mOxPhos $(49,50)$.

\section{CONCLUSIONS}

Chemiosmosis proposal was a "mirage", with little grounding in reality. This is because at steady state, chemiosmosis requires the mitochondrial matrix (which lacks 


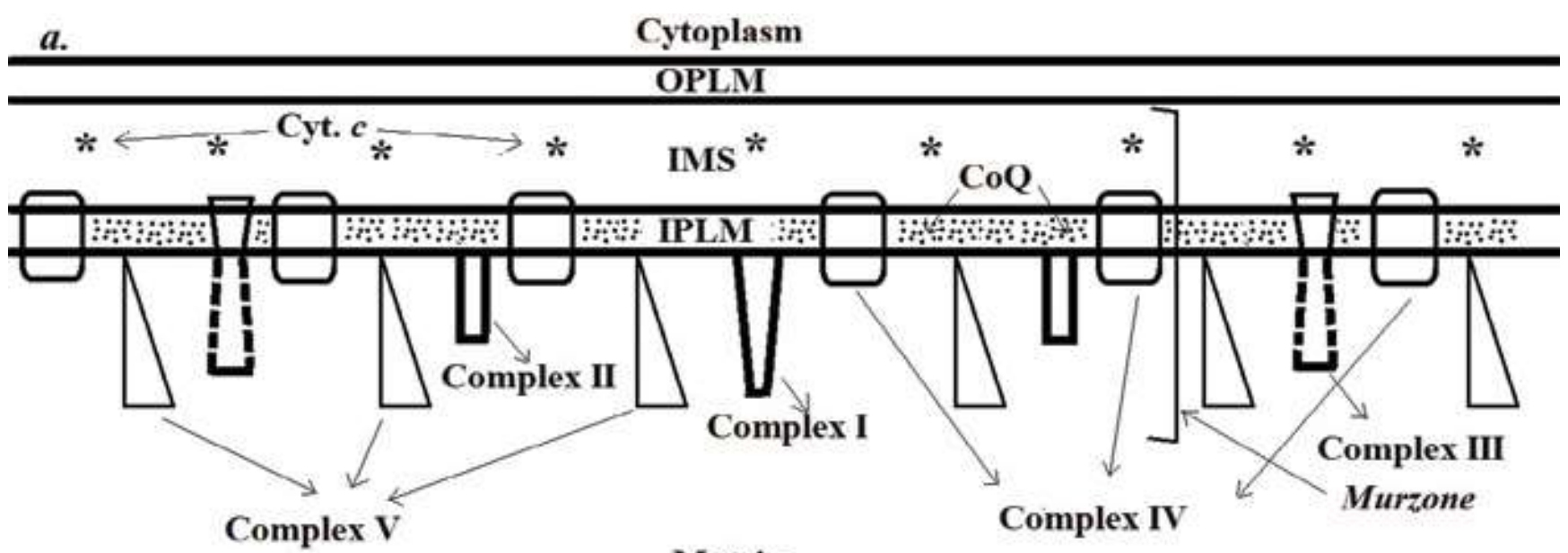

\section{Matrix}

b.

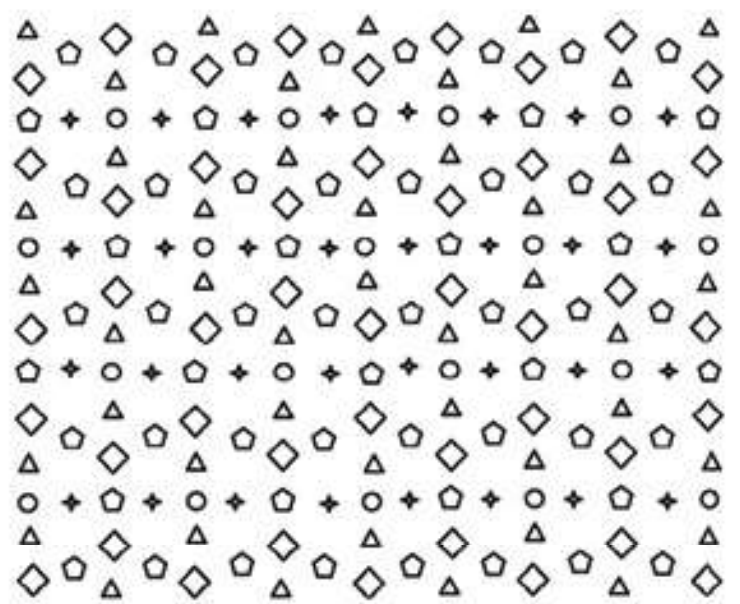

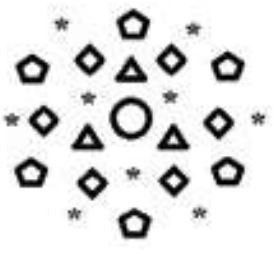

Complex I

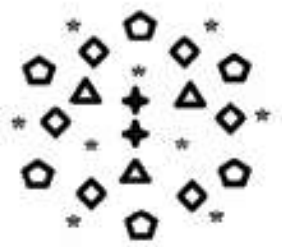

Complex II

Figure 5. a. Schematic cross-sectional view of the mitochondrial membranes is depicted to show the relative distribution and rough dimensions of various complexes' penetration into the matrix in murzone. (Figure is not drawn to scale, but for deriving semi-quantitative impressions alone.) The ratio depicted is a I:II:III:IV:V:Cyt. c = 1:2:2:6:6:9, based on a subjective average of Gupte et al (19), Schwerzmann et al (20) data. OPLM and IPLM connote outer and inner phospholipid membrane and IMS is inter-membrane space. The putative enzymatic sources of superoxide are drawn in bold. Complex III's role needs to be redefined/re-charted. It can be seen that the erstwhile EPCR hypothesis has little scope for any effective functioning with such a distribution. For details, please refer Chapter 2. b. Surface view depicting relative distribution densities of the complexes on the inner membrane. The images are not drawn to give acurate dimentions or precise spatial arrangements, but only to indicate an overall distribution. Depiction key: Complex I - circle, Complex II - plus star, Complex III - triangle, Complex IV-rhombus, and Complex V-pentagon, Cytochrome c-asterisk. Cytochrome c is not shown in the overall view (to retain clarity in presentation). In the individual systems shown on the right, Gupte's values are weighted.

modularity and synchronicity of the necessary components) to harbor practically zilch protons (for building the pmf!) and several orders higher protons (for the proton pumping proteins to work!), both at the same instant. Further, in steady state, he potential would be continuous and of a constant polarity. In such a scenario, Biomed Rev 28, 2017 there would be little mechanisms to harvest the potential because there would be no discrete temporal windows for the proteins (both proton pumps and Complex V) to sense the field, alter their conformations and return to their native states. Therefore, the erstwhile perception must make way for a new one. When a generator/motor runs, it may pro- 
duce sound/exhaust. But it is not the sound/exhaust that does the useful work. Similarly, the chemical reactions occurring near the inner mitochondrial membrane lead to phosphorylations and build up TMP. Such a TMP is analogous to the sound/exhaust of the generator/motor! If esthetic perspectives are overlooked and kinetics, thermodynamics and probability are given more "merit", murburn concept explanation is a potentially worthy avenue for further exploration. The stochastic reaction scheme proposed herein is an evolutionarily facile paradigm that gels with known structure and newly attributed functional correlations.The new proposal also explains why the earlier hunts for "enzyme-linked reactive intermediates" were unsuccessful. Currently, it is envisaged that murburn concept would also play significant roles in several biological responses which involve the interplay of physical stimuli to generate chemical responses. Thus, murburn concept necessitates a paradigm shift in biochemistry and medicine that DROS could be catalytically useful in routine physiology and metabolism.

\section{ACKNOWLEDGMENTS}

The work was powered by Satyamjayatu: The Science and Ethics Foundation, India. The author is thankful for dis-cussions and assistance from former group members, Dr. Abhinav Parashar and Vivian David Jacob.

\section{REFERENCES}

1. Nicholls DG, Ferguson SJ. Bioenergetics 2. London: Academic Press, 1992.

2. Slater EC. Mechanism of phosphorylation in the respiratory chain. Nature 1953;172:975-978.

3. Mitchell P. Coupling of phosphorylation to electron and hydrogen transfer by a chemi-osmotic type of mechanism. Nature 1961;191:144-148.

4. Boyer PD. Phosphohistidine. Science 1963;141:11471153. DOI: $10.1126 /$ science.141.3586.1147.

5. Jagendorf AT, Uribe E. ATP formation caused by acidbase transition of spinach chloroplasts. Proc Natl Acad Sci USA 1966;55:170-177.

6. Reid R, Moyle J, Mitchell P. Synthesis of adenosine triphosphate by a protonmotive force in rat liver mitochondria. Nature 1966;212:257-258.

7. Liberman E, Topaly V, Tsofina L. Mechanism of coupling of oxidative phosphorylation and the membrane potential of mitochondria. Nature 1969;222:1076-1078.

8. Racker E, Stoeckenius W. Reconstitution of purple membrane vesicles catalyzing light-driven proton uptake and adenosine triphosphate formation. J Biol Chem 1974;249:662-663.

9. Brand MD, Lehninger AL. $\mathrm{H}+/ \mathrm{ATP}$ ratio during ATP hydrolysis by mitochondria: modification of the chemi- osmotic theory. Proc Natl Acad Sci USA 1977;74:19551959.

10. Borst P. Edward Charles Slater. 16 January 1917 - 26 March 2016. Biographical Memoirs of Fellows of the Royal Society. 2017. DOI: 10.1098/rsbm.2016.0024

11. Slater E. An evaluation of the Mitchell hypothesis of chemiosmotic coupling in oxidative and photosynthetic phosphorylation. Eur J Biochem 1967;1:317-326. DOI: 10.1111/j.1432-1033.1967.tb00076.x

12. Slater $E$. The mechanism of the conservation of energy of biological oxidations. FEBS $J$ 1987;166:489-504. DOI: 10.1111/j.1432-1033.1987.tb13542.x

13. Ling GN. Oxidative phosphorylation and mitochondrial physiology: a critical review of chemiosmotic theory, and reinterpretation by the association-induction hypothesis. Physiol Chem Phys 1981;13:29-96.

14. Wainio W. An assessment of the chemiosmotic hypothesis of mitochondrial energy transduction. Int Rev Cytol 1985;96:29-50. DOI: 10.1016/S0074-7696(08)60593-8

15. Montellano PRO. Cytochrome P450: Structure, Mechanism, and Biochemistry. 3rd edition. New York, Kluwer, Academic Plenum Publishers, 2005.

16. Lehninger AL, Nelson DL, Cox M. Principles of Biochemistry. Palgrave Macmillan Ltd, 2004.

17. Berg JM, Tymoczko JL, Stryer L. Biochemistry, 5th edition. 2002.

18. Voet D, Voet JG. Biochemistry, 4th edition. Wiley, Hoboken, NJ, USA, 2011.

19. Gupte S, Wu E-S, Hoechli L, Hoechli M, Jacobson K, Sowers AE, et al. Relationship between lateral diffusion, collision frequency, and electron transfer of mitochondrial inner membrane oxidation-reduction components. Proc Natl Acad Sci U S A. 1984;81(9):2606-2610.

20. Schwerzmann K, Cruz-Orive LM, Eggman R, Sänger A, Weibel ER. Molecular architecture of the inner membrane of mitochondria from rat liver: a combined biochemical and stereological study. J Cell Biol 1986;102:97-103. DOI: $10.1083 /$ jcb.102.1.97

21. Biegel CM, Gould JM. Kinetics of hydrogen ion diffusion across phospholipid vesicle membranes. Biochemistry 1981;20:3474-3479. DOI: 10.1021/bi00515a026

22. Nicholls DG. Mitochondrial membrane potential and aging. Aging Cell 2004;3:35-40. DOI: 10.1111/j.14749728.2003.00079.x

23. Nath S. Beyond the chemiosmotic theory: Analysis of key fundamental aspects of energy coupling in oxidative phosphorylation in the light of a torsional mechanism of 
energy transduction and ATP synthesis - Invited review Part 1. J Bioenerg Biomemb 2010;42:293-300.

24. Nath S. Beyond the chemiosmotic theory: Analysis of key fundamental aspects of energy coupling in oxidative phosphorylation in the light of a torsional mechanism of energy transduction and ATP synthesis - Invited review part 2. J Bioenerg Biomemb 2010;42:301-309. DOI: 10.1007/s10863-010-9296-5

25. Cross R, Taggart JV, Covo G, Green D. Studies on the cyclophorase system VI. The coupling of oxidation and phosphorylation. J Biol Chem 1949;177:655-678.

26. Copenhaver J, Lardy HA. Oxidative phosphorylations: Pathways and yield in mitochondrial preparations. J Biol Chem 1952;195:225-238.

27. Chance B, Williams G. Respiratory enzymes in oxidative phosphorylation I. Kinetics of oxygen utilization. J Biol Chem 1955;217:383-394.

28. Lemasters J. The ATP-to-oxygen stoichiometries of oxidative phosphorylation by rat liver mitochondria. An analysis of ADP-induced oxygen jumps by linear nonequilibrium thermodynamics. J Biol Chem 1984;259:1312313130.

29. Beavis AD, Lehninger AL. The upper and lower limits of the mechanistic stoichiometry of mitochondrial oxidative phosphorylation. FEBS J 1986;158:315-322. DOI: 10.1111/j.1432-1033.1986.tb09753.x

30. Stoner CD. Determination of the $\mathrm{P} / 2 \mathrm{e}$-stoichiometries at the individual coupling sites in mitochondrial oxidative phosphorylation. Evidence for maximum values of 1.0, 0.5, and 1.0 at sites 1, 2, and 3. J Biol Chem 1987;262:10445-10453.

31. Toth PP, Sumerix KJ, Ferguson-Miller S, Suelter CH. Respiratory control and ADP: O coupling ractions of isolated chick heart mitochondria. Arch Biochem Biophys 1990;276:199-211.

32. Lee C, Gu Q, Xiong Y, Mitchell R, Ernster L. P/O ratios reassessed: mitochondrial $\mathrm{P} / \mathrm{O}$ ratios consistently exceed 1.5 with succinate and 2.5 with NAD-linked substrates. FASEB J 1996;10:345-350. DOI: 10.1016/j.bbabio.2004.09.004

33. Watt IN, Montgomery MG, Runswick MJ, Leslie AG, Walker JE. Bioenergetic cost of making an adenosine triphosphate molecule in animal mitochondria. Proc Nat Acad Sci USA 2010;107:16823-16827. DOI: 10.1073/ pnas. 1011099107

34. Chance B, Williams G. The respiratory chain and oxidative phosphorylation. Adv Enzymol Relat Areas Mol Biol
1956;17:65-134. DOI: 10.1002/9780470122624.ch2

35. Estabrook RW: Mitochondrial respiratory control and the polarographic measurement of ADP: $O$ ratios. In: Estabrook RE, Pullman MF (Eds), Methods in Enzymology. Volume 10. New York: Academic Press, 1967; pp 41-47.

36. Manoj KM, Parashar A, Gade SK, Venkatachalam A. Functioning of microsomal cytochrome P450s: Murburn concept explains the metabolism of xenobiotics in hepatocytes. Front Pharmacol 2016;7:161. DOI: 10.3389/ fphar.2016.00161

37. Szewczyk A, Wojtczak L. Mitochondria as a pharmacological target. Pharmacolo Rev 2002;54:101-127.

38. Parikh S, Saneto R, Falk MJ, Anselm I, Cohen BH, Haas R. A modern approach to the treatment of mitochondrial disease. Curr Treat Options Neurol 2009;11:414-430.

39. Scatena R. Mitochondria and drugs. Adv Exp Med Biol 2012;942:329-346.

40. Picard M, Wallace DC, Burelle Y. The rise of mitochondria in medicine. Mitochondrion. 2016;30(105-116. doi: 10.1016/j.mito.2016.07.003

41. Wheaton WW, Weinberg SE, Hamanaka RB, Soberanes S, Sullivan LB, Anso E, Glasauer A, et al. Metformin inhibits mitochondrial complex I of cancer cells to reduce tumorigenesis. eLife. 2014;3(e02242. doi: 10.7554/ eLife.02242.001

42. Gohil VM, Sheth SA, Nilsson R, Wojtovich AP, Lee JH, Perocchi F, Chen W, et al. Nutrient-sensitized screening for drugs that shift energy metabolism from mitochondrial respiration to glycolysis. Nat Biotechnol 2010;28:249255. DOI: $10.1038 /$ nbt. 1606

43. Venkatachalam A, Parashar A, Manoj KM. Functioning of drug-metabolizing microsomal cytochrome P450s. 1. In silico probing of proteins suggest that the distal heme 'active site' pocket plays a relatively 'passive role' in some enzyme-substrate interactions. In Silico Pharmacol 2016;4:1. DOI: 10.1186/s40203-016-0016-7

44. Bhagwat SV, Mullick J, Raza H, Avadhani NG. Constitutive and inducible cytochromes $\mathrm{P} 450$ in rat lung mitochondria: xenobiotic induction, relative abundance, and catalytic properties. Toxicol Appl Pharmacol 1999;156:231-240. DOI: 10.1006/taap.1999.8646

45. Robin M-A, Anandatheerthavarada HK, Fang J-K, Cudic M, Otvos L, Avadhani NG. Mitochondrial targeted cytochrome P450 2E1 (P450 MT5) contains an intact N terminus and requires mitochondrial specific electron transfer proteins for activity. J Biol Chem 2001;276:24680- 
24689. DOI: 10.1074/jbc.M100363200

46. Sangar MC, Bansal S, Avadhani NG. Bimodal targeting of microsomal cytochrome P450s to mitochondria: implications in drug metabolism and toxicity. Expert Opin Drug Metab Toxicol 2010;6(10):1231-1251. DOI: $10.1517 / 17425255.2010 .503955$

47. Mitchell SC. Xenobiotic conjugation with phosphate a metabolic rarity. Xenobiotica 2016;46:743-756. DOI: 10.3109/00498254.2015.1109161

48. Semak I, Korik E, Antonova M, Wortsman J, Slominski A.
Metabolism of melatonin by cytochrome $\mathrm{P} 450 \mathrm{~s}$ in rat liver mitochondria and microsomes. J Pineal Res 2008;45:515523. DOI: 10.1111/j.1600-079X.2008.00630.x

49. Manoj KM. Mitochondrial oxidative phosphorylation: Debunking the concepts of electron transport chain, proton pumps, chemiosmosis and rotary ATP synthesis. arXiv preprint 2017; arxXiv:1703.05826.

50. Manoj KM. Murburn concept: A facile explanation for oxygen-centered cellular respiration. arXiv preprint 2017; arXiv:1703.05827. 